\title{
Can We Improve Sleep Quality by Changing the Way We Ventilate Patients?
}

\author{
Marios Roussos · Sairam Parthasarathy • \\ Najib T. Ayas
}

Received: 20 September 2009/Accepted: 22 September 2009/Published online: 21 October 2009

(C) Springer Science+Business Media, LLC 2009

Sleep is an integral part of daily life. Both disrupted and restricted sleep adversely affect well-being and predispose to chronic medical problems [1]. For example, in epidemiologic studies, women reporting 5 or fewer hours of sleep per night are at significantly increased risk of incident cardiovascular disease and diabetes over a 10 -year time period $[2,3]$.

Critically ill mechanically ventilated patients have long been known to have poor sleep quality [4], but the potential importance of sleep disturbance in these patients is only now starting to be recognized $[5,6]$. Sleep deprivation may adversely affect respiratory, cognitive, cardiovascular, endocrine, and immune function in normal subjects [7-9]; altered sleep architecture may be associated with an increased incidence of delirium in ICU patients [10]. Furthermore, in the case of long-term positive-pressure therapy, adherence to the treatment may be influenced by how it affects sleep [11].

There are numerous factors that adversely affect sleep quality in critically ill patients. Noise, nursing care, circadian rhythm disruption, and light exposure have all been implicated [12, 13], as have severity of illness and

\footnotetext{
M. Roussos

Division of Critical Care Medicine, University of British Columbia, 2775 Laurel Street, Vancouver, BC V5Z 1M9, Canada

S. Parthasarathy

Southern Arizona Veterans Health Care System,

Tucson, AZ, USA

\section{N. T. Ayas $(\bowtie)$}

Divisions of Respiratory and Critical Care Medicine,

University of British Columbia, 2775 Laurel Street,

Vancouver, BC V5Z 1M9, Canada

e-mail: Najib.Ayas@vch.ca
}

medications [14]. Interest, however, has recently turned toward the mode and settings of mechanical ventilation as a cause of sleep disturbance [15].

Major causes of sleep disturbance associated with mechanical ventilation include patient-ventilator asynchronies [16], central apneas due to overventilation [17], and inadequate ventilatory support due to improper settings or air leaks leading to increased respiratory effort [18]. Therefore, there is a renewed interest in finding novel ways of adequately ventilating patients while minimizing sleep disturbance.

In a previous issue of Lung, Crisafulli et al. [19] presented the findings of a pilot study comparing a newer mode of noninvasive ventilation, average volume assured pressure support (AVAPS), to noninvasive pressure support (NIV-PS) therapy in nine stable hypercapnic COPD patients. AVAPS differs from NIV-PS in its ability to ensure more consistent minute ventilation by slowly adjusting inspiratory positive airway pressure (IPAP) to achieve a preset tidal volume. Therefore, there is a theoretical benefit in that this mode of ventilation could improve nocturnal ventilation in hypercapnic patients, leading to improvements in $\mathrm{CO}_{2}$ retention and sleep efficiency. Specifically, they looked at differences in nocturnal ventilation, sleep efficiency, and compliance with therapy in patients randomized to 5 days of one mode of ventilation, who then crossed over to 5 days of the other mode. They found that AVAPS resulted in a trend toward improved nocturnal minute ventilation as well as a statistically significant improvement in subjective sleep quality as measured by a questionnaire. Although two previous studies demonstrated an increase in nocturnal minute ventilation with AVAPS in patients with chronic respiratory failure [20] and obesity hypoventilation [21], neither study was able to show an improvement in sleep efficiency 
as measured by polysomnography. While there are numerous possible explanations for this discrepancy, there is one in particular that bears mentioning. Whereas the previous studies used polysomnography to assess sleep efficiency, Crisafulli's study employed a diurnal hypersomnia questionnaire. It is thus possible that the previous studies on AVAPS using polysomnography were not able to detect subtle changes in sleep architecture that patients may nevertheless subjectively feel over the long term.

It is crucial that future studies looking at the effects of mechanical ventilation on sleep efficiency use sleep questionnaires that have demonstrated acceptable levels of reliability and validity, while also using objective measures such as polysomnography, continuous oxygen saturation, or end-tidal $\mathrm{CO}_{2}$ monitoring that may help determine the mechanism by which sleep efficiency is improved.

Recent developments such as the renewed interest of esophageal balloons [22] may help clinicians and researchers titrate their nocturnal ventilation in a more physiologic fashion that benefits sleep [23]. Also, neurally adjusted ventilatory assist (NAVA) mode of ventilation [24] may allow one to minimize asynchronies [25] and overventilation [26], while ensuring adequate ventilation during sleep, though this remains speculative.

Finally, more work will be needed to determine whether an improvement in sleep quality will have an impact on meaningful patient outcomes. For example, will improving sleep quality improve compliance with treatment, reduce delirium, decrease susceptibility to infections, reduce time to extubation, and improve patient mortality? Nevertheless, papers such as the one by Crisafulli et al. may awaken clinicians and researchers to a potentially important field of study in the critical care unit.

\section{References}

1. Al Lawati NM, Patel SR, Ayas NT (2009) Epidemiology, risk factors, and consequences of obstructive sleep apnea and short sleep duration. Prog Cardiovasc Dis 51(4):285-293

2. Ayas NT, White DP, Al-Delaimy WK, Manson JE, Stampfer MJ, Speizer FE, Patel S, Hu FB (2003) A prospective study of selfreported sleep duration and incident diabetes in women. Diabetes Care 26(2):380-384

3. Ayas NT, White DP, Manson JE, Stampfer MJ, Speizer FE, Malhotra A, Hu FB (2003) A prospective study of sleep duration and coronary heart disease in women. Arch Intern Med 163(2):205-209

4. Hardin KA (2009) Sleep in the ICU: potential mechanisms and clinical implications. Chest 136:284-294

5. Cabello B, Parthasarathy S, Mancebo J (2007) Mechanical ventilation: let us minimize sleep disturbances. Curr Opin Crit Care 13:20-26

6. Figueroa-Ramos MI, Arroyo-Novoa CM, Lee KA, Padilla G, Puntillo KA (2009) Sleep and delirium in ICU patients: a review of mechanisms and manifestations. Intensive Care Med 35:781795

7. Salas RE, Gamaldo CE (2008) Adverse effects of sleep deprivation in the ICU. Crit Care Clin 24:461-476 v-vi

8. Spiegel K, Leproult R, Van Cauter E (1999) Impact of sleep debt on metabolic and endocrine function. Lancet 354(9188):1435-1439

9. Meier-Ewert HK, Ridker PM, Rifai N, Regan MM, Price NJ, Dinges DF, Mullington JM (2004) Effect of sleep loss on Creactive protein, an inflammatory marker of cardiovascular risk. J Am Coll Cardiol 43(4):678-683

10. Trompeo A, Vidi Y, Locane M, Braghiroli A, Rana N, Rizzuto A et al (2005) The influence of sleep disorders on the occurrence of delirium in critically ill patients. Intensive Care Med Suppl:S94 (Abstract of Annual Congress of European Society of Intensive Care Medicine, Amsterdam, Netherlands)

11. Meurice JC, Dore P, Paquereau J, Neau JP, Ingrand P, Chavagnat JJ, Patte F (1994) Predictive factors of long-term compliance with nasal continuous positive airway pressure treatment in sleep apnea syndrome. Chest 105:429-433

12. Freedman NS, Gazendam J, Levan L, Pack AI, Schwab RJ (2001) Abnormal sleep/wake cycles and the effect of environmental noise on sleep disruption in the intensive care unit. Am J Respir Crit Care Med 163:451-457

13. Freedman NS, Kotzer N, Schwab RJ (1999) Patient perception of sleep quality and etiology of sleep disruption in the intensive care unit. Am J Respir Crit Care Med 159:1155-1162

14. Drouot X, Cabello B, d'Ortho MP, Brochard L (2008) Sleep in the intensive care unit. Sleep Med Rev 12:391-403

15. Ozsancak A, D'Ambrosio C, Garpestad E, Schumaker G, Hill NS (2008) Sleep and mechanical ventilation. Crit Care Clin 24:517531 vi-vii

16. Bosma K, Ferreyra G, Ambrogio C, Pasero D, Mirabella L, Braghiroli A, Appendini L, Mascia L, Ranieri VM (2007) Patient-ventilator interaction and sleep in mechanically ventilated patients: pressure support versus proportional assist ventilation. Crit Care Med 35:1048-1054

17. Parthasarathy S, Tobin MJ (2002) Effect of ventilator mode on sleep quality in critically ill patients. Am J Respir Crit Care Med 166:1423-1429

18. Teschler H, Stampa J, Ragette R, Konietzko N, Berthon-Jones M (1999) Effect of mouth leak on effectiveness of nasal bilevel ventilatory assistance and sleep architecture. Eur Respir J 14:1251-1257

19. Crisafulli E, Manni G, Kidonias M, Trianni L, Clini EM (2009) Subjective sleep quality during average volume assured pressure support (AVAPS) ventilation in patients with hypercapnic COPD: a physiological pilot study. Lung 187:299-305

20. Ambrogio C, Lowman X, Kuo M, Malo J, Prasad AR, Parthasarathy S (2009) Sleep and non-invasive ventilation in patients with chronic respiratory insufficiency. Intensive Care Med 35:306-313

21. Storre JH, Seuthe B, Fiechter R, Milioglou S, Dreher M, Sorichter S, Windisch W (2006) Average volume-assured pressure support in obesity hypoventilation: a randomized crossover trial. Chest 130:815-821

22. Talmor D, Sarge T, Malhotra A, O'Donnell CR, Ritz R, Lisbon A, Novack V, Loring SH (2008) Mechanical ventilation guided by esophageal pressure in acute lung injury. N Engl J Med 359:2095-2104

23. Fanfulla F, Delmastro M, Berardinelli A, Lupo ND, Nava S (2005) Effects of different ventilator settings on sleep and inspiratory effort in patients with neuromuscular disease. Am J Respir Crit Care Med 172:619-624

24. Sinderby C, Navalesi P, Beck J, Skrobik Y, Comtois N, Friberg S, Gottfried SB, Lindström L (1999) Neural control of mechanical ventilation in respiratory failure. Nat Med 5:1433-1436 
25. Beck J, Campoccia F, Allo JC, Brander L, Brunet F, Slutsky AS, Sinderby C (2007) Improved synchrony and respiratory unloading by neurally adjusted ventilatory assist (NAVA) in lunginjured rabbits. Pediatr Res 61:289-294
26. Sinderby C, Beck J, Spahija J, de Marchie M, Lacroix J, Navalesi P, Slutsky AS (2007) Inspiratory muscle unloading by neurally adjusted ventilatory assist during maximal inspiratory efforts in healthy subjects. Chest 131:711-717 